\title{
Vertical and horizontal movement patterns of scyphozoan jellyfish in a fjord-like estuary
}

\author{
Pamela E. Moriarty ${ }^{1}$, Kelly S. Andrews ${ }^{2, *}$, Chris J. Harvey ${ }^{2}$, Mitsuhiro Kawase ${ }^{3}$ \\ ${ }^{1}$ Kenyon College, Departments of Biology and Mathematics, Gambier, Ohio 43022, USA \\ ${ }^{2}$ Northwest Fisheries Science Center, National Marine Fisheries Service, National Oceanic and Atmospheric Administration, \\ 2725 Montlake Blvd E, Seattle, Washington 98112, USA \\ ${ }^{3}$ School of Oceanography, University of Washington, Box 355351, Seattle, Washington 98195, USA
}

ABSTRACT: Despite their important functional role in marine ecosystems, we lack much information about jellyfish, including basic research on their swimming behavior. Here we used acoustic telemetry to obtain detailed behavioral data on 2 scyphozoans, lion's mane jellyfish Cyanea capillata and fried-egg jellyfish Phacellophora camtschatica, in Hood Canal, Puget Sound, Washington, USA. Individual variation was high in both the short-term (hours) and long-term (days) data, although several patterns of behavior emerged. Lion's mane jellyfish performed diel vertical migrations over the longer time period, but their depth did not vary with tidal stage. Additionally, horizontal swimming speeds varied with diel period and tidal stage for both lion's mane and fried-egg jellyfish. Lion's mane jellyfish swam faster during the night than day, whereas fried-egg jellyfish swam faster during the day. Both species had the highest swimming rates during flood tides. Jellyfish clearly exhibited active swimming behaviors and were not passively planktonic. Net and cumulative distances traveled suggest that Hood Canal may be a sink for jellyfish, potentially exacerbating effects of population blooms on the ecosystem. Our findings provide mixed support for previous studies reporting diel vertical migrations in other jellyfish species, and provide evidence that jellyfish are capable of more advanced swimming behaviors than often thought.

KEY WORDS: Acoustic telemetry - Cyanea capillata • Phacellophora camtschatica Diel vertical migration · Hypoxia

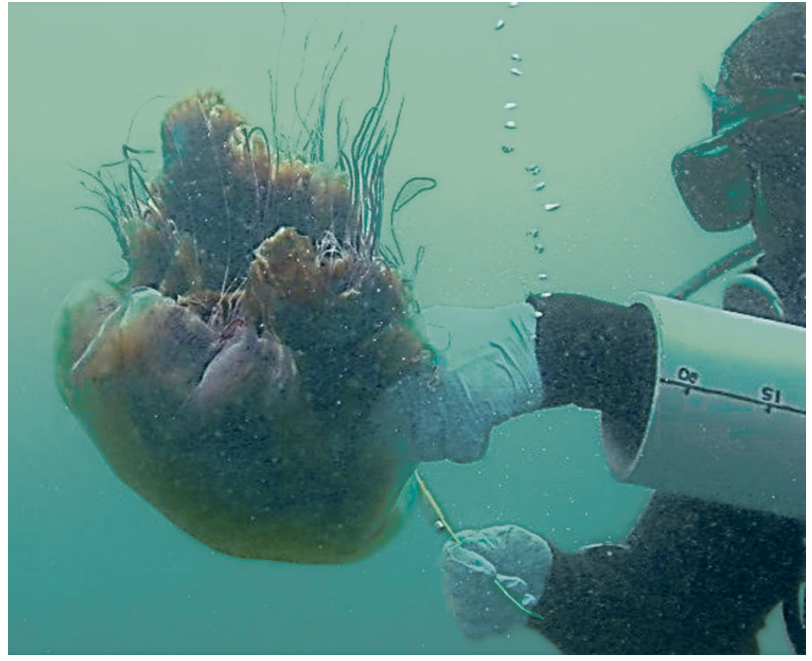

A researcher attaches an acoustic transmitter to the underside of a lion's mane jellyfish, Cyanea capillata, in Hood Canal, WA, USA.

Photo: Chris J. Harvey

\section{INTRODUCTION}

A growing body of evidence indicates that jellyfish (phylum Cnidaria, class Scyphozoa) play a large role in marine systems (Condon et al. 2012). Jellyfish form large seasonal or cyclical components of the pelagic biomass in many coastal communities (Purcell et al. 2007, Rice 2007), and act as predators or prey for a wide range of species (Pauly et al. 2009). They may compete with commercially and ecologically important forage fish for zooplankton prey, and feed on pelagic stages of commercially and ecologically 
important invertebrates and fishes (Purcell et al. 2007, Richardson et al. 2009, Hays et al. 2012). Jellyfish may serve as indicators of ecosystem structure and functioning in several Northeast Pacific marine systems (Samhouri et al. 2009), and their population blooms can change the energy flow and structure of marine food webs (Condon et al. 2011). Some researchers hypothesize that jellyfish populations are increasing in degraded coastal marine habitats throughout the world (Richardson et al. 2009), although the exact causes remain uncertain and may simply be related to decadal population cycles (Purcell et al. 2007). Their ability to tolerate warm, hypoxic, eutrophic conditions has the potential to exacerbate their effects on prey and competitors in degraded systems (Shoji et al. 2005). Increases in jellyfish populations can lead to losses in ecosystem services such as fisheries, tourism, aquaculture, and power generation (Purcell \& Arai 2001, Purcell et al. 2007, Pauly et al. 2009, Richardson et al. 2009).

Despite the role of jellyfish in marine systems, we lack much basic information on their ecology, including their abundance, spatial distribution, behavior, and diets (Houghton et al. 2006, Bastian et al. 2011). Such information is necessary to objectively determine their impacts and potential usefulness as indicator species. Monitoring the movement of organisms, especially marine organisms, has historically been difficult. This has led to the development of a variety of monitoring methods including mark-recapture techniques (Glover et al. 2008, Hovel \& Wahle 2010), otolith microchemistry (Gillanders 2005), analyzing presence of parasites (MacKenzie 2002), and studying spatial and temporal changes in the distribution of population abundances (Shoji et al. 2010). However, none of these methods is particularly informative on where individuals spend time in the water column or which habitats they frequently visit. Advances in satellite, radio, and acoustic telemetry technology have increased our ability to monitor both large- and small-scale movements of fish (Irving \& Modde 2000, Simpfendorfer et al. 2010) and other marine species (Baumgartner \& Mate 2005, Barnett et al. 2010, Smith et al. 2010), which has led to a large increase in our knowledge of where many fish and invertebrates spend their time and when they move between habitats.

Previous work on jellyfish has produced evidence that they perform diel vertical migrations (Bamstedt et al. 2003, Kaartvedt et al. 2007, Parker-Stetter \& Horne 2009, Parker-Stetter et al. 2009), possibly in response to light intensity (Dupont et al. 2009), and at least one species of jellyfish, the moon jellyfish Aure- lia labiata, uses vertical migration to facilitate horizontal migration (Albert 2007). However, the vast majority of these studies have taken place at the population level, as following the movements of individual jellyfish is difficult. Tagging and tracking, a common method for studying movements of nongelatinous species, is beginning to be applied to jellyfish, but presents logistical challenges, which are gradually being overcome through novel methodological improvements (Hays et al. 2008, 2012, Gordon \& Seymour 2009). Only recently have researchers successfully and consistently tracked individual jellyfish for more than 24 consecutive hours (Kaartvedt et al. 2011, Hays et al. 2012).

For this study, we combined active acoustic tracking with passive acoustic monitoring to describe local-scale vertical and horizontal movement patterns of 2 species of scyphozoan jellyfish in Puget Sound, a large, fjord-like estuarine system in the northwestern corner of the continental US. Active tracking of individuals provides fine-scale data on the movement of organisms (Andrews et al. 2009, Simpfendorfer et al. 2010); however, this method is labor-intensive, which typically causes the number of animals tracked to be small and tracking time to be relatively short. To provide more information, active tracking can be combined with the deployment of an array of passive receivers that continuously detect all acoustic transmitters within the range of detection. This provides individual presence/absence and depth data over longer temporal scales and can be established across larger spatial scales (Andrews et al. 2010, Payne et al. 2010). Such data will provide helpful information about jellyfish habitat use in Puget Sound, where relationships between jellyfish and other pelagic fauna have largely been overlooked (Rice 2007).

Here we addressed 3 questions in order to begin investigating the role of jellyfish in Puget Sound: (1) Do individual jellyfish show diel vertical movement behavior? (2) Are their vertical movements correlated with environmental parameters such as temperature, salinity, or dissolved oxygen? (3) Do jellyfish move passively with tidal currents or are they able to move independently?

\section{MATERIALS AND METHODS}

\section{Study species}

For this study, we focused on two of the largest and most common scyphozoan species in Puget Sound: 
the lion's mane jellyfish Cyanea capillata and the fried-egg jellyfish Phacellophora camtschatica. These species were selected due to both their abundance and their size, as they were substantive enough to allow for the attachment of acoustic tags. Pilot trials conducted in large tanks and in shallow, nearshore waters indicated that lion's mane and fried-egg jellyfish with bell diameters $\geq 20 \mathrm{~cm}$ and $\geq 25 \mathrm{~cm}$, respectively, were able to swim easily and maintain buoyancy when outfitted with tags following the tagging methods described below.

\section{Study location}

Our study occurred in the Hood Canal basin of Puget Sound (Fig. 1). Hood Canal is a long, narrow, steeply walled basin, with mean and maximum depths of $54 \mathrm{~m}$ and $183 \mathrm{~m}$, respectively. Circulation in the system is poor, relative to other parts of Puget Sound (PSP 2008). Estimated water residence times average 80 to $90 \mathrm{~d}$ (Babson et al. 2006, Sutherland et al. 2011), due in part to a shallow sill at the head of the basin that restricts exchange with the rest of
Puget Sound, and vertical mixing is constrained by salinity gradients due to riverine inputs. These factors and anthropogenic activities contribute to frequent periods of summer and fall hypoxia (dissolved oxygen $<2.0 \mathrm{mg} \mathrm{l}^{-1}$ ) in the southern portion of Hood Canal and in lower parts of the water column (PSP 2008)

Our study was centered at Sund Rock (Fig. 1), a small marine reserve located along the western side of Hood Canal. All jellyfish were tagged within $100 \mathrm{~m}$ of Sund Rock, typically at depths $<15 \mathrm{~m}$. The spatial extent of active tracking followed their movement patterns during the $\sim 24 \mathrm{~h}$ following tagging. The spatial extent of passive tracking corresponded to 42 stations arrayed throughout Hood Canal (Fig. 1), where acoustic receivers were fixed.

\section{Tagging of jellyfish}

On 4 sampling dates in 2010 (23 June, 7 and 21 July, and 12 August), we used SCUBA to locate and tag jellyfish with $\mathrm{Vemco}^{\circledR}$ V9P-1L acoustic transmitters with pressure sensors (diameter: $9 \mathrm{~mm}$; length:

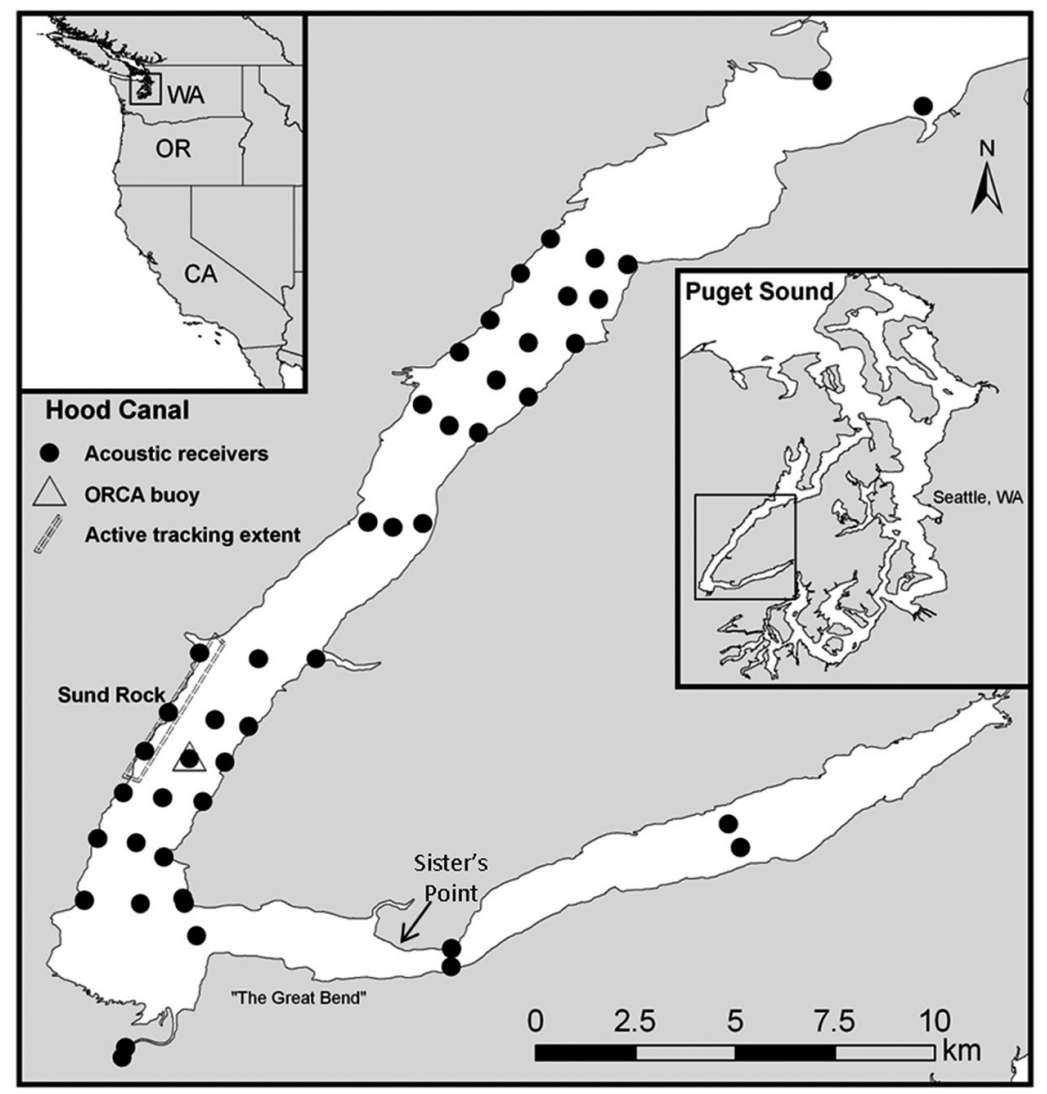

Fig. 1. Locations of passive acoustic receivers, tagging site at Sund Rock, the ORCA buoy, and the spatial extent of $24 \mathrm{~h}$ active tracking in Hood Canal, Washington, USA 
$42 \mathrm{~mm}$; weight in water: $2.7 \mathrm{~g} ; 185 \mathrm{~d}$ of battery life; $143 \mathrm{~dB}$ power output). Transmitters (hereafter 'tags') emitted a train of 'pings' at $69 \mathrm{kHz}$ randomly every 40 to $120 \mathrm{~s}$. These pings contained a specific ID code and provided a value of the sensor's depth (every second set of pings) allowing users to identify individuals and collect 3-dimensional data. Each tag was inserted into a $28 \mathrm{~mm}$ long sheath of $6.35 \mathrm{~mm}$ inside diameter latex tubing. A $19 \mathrm{~cm}$ long cable tie was then inserted in between the tubing and tag. Upon locating a jellyfish underwater, we measured its bell diameter $( \pm 5 \mathrm{~cm})$ and noted its overall condition; we did not tag jellyfish that showed any external signs of injury or senescence. We then gently turned the jellyfish on its side or upside down, threaded the cable tie around the coronal muscle in between 2 radial muscles, and loosely fastened the cable tie, being careful to avoid getting air bubbles trapped in the jellyfish's bell. Jellyfish were immediately released and observed to ensure they continued to swim as prior to tagging. We only tagged lion's mane jellyfish with $\geq 20 \mathrm{~cm}$ bell diameter and fried-egg jellyfish with $\geq 25 \mathrm{~cm}$ bell diameter.

\section{Active tracking}

Immediately following tagging, we began to actively track all jellyfish using Vemco ${ }^{\odot}$ VR100 and VR28 acoustic receivers deployed from a small boat. The VR100 hydrophone was placed $\sim 1.5 \mathrm{~m}$ below the surface of the water on an aluminum pole secured to the boat, while the VR28 was towed below the surface behind the boat moving $<4 \mathrm{~km} \mathrm{~h}^{-1}$. Tracking numerous tags in the same location can lead to collisions of multiple acoustic transmissions, so in order to enhance the number of detections, we deployed 4 fixed passive receivers (Vemco ${ }^{\circledR}$ VR2W) during the active tracking sessions on 7 and 21 July. VR2Ws were deployed immediately prior to tagging operations approximately every $\mathrm{km}$ along a $3 \mathrm{~km}$ stretch of the coastline centered on Sund Rock (Fig. 1). We actively tracked individual jellyfish for $\sim 24 \mathrm{~h}$ following tagging by making continuous north/south sweeps approximately every 30 min to get locations and depths of each jellyfish as they moved in various directions. The northerly and southerly extents of each transect were based on the locations of the jellyfish (Fig. 1).

In order to collect water quality data, we performed bottom casts of a CTD profiler (Sea-Bird Electronics SEACAT 19plusV2 profiler) with dissolved oxygen sensor (SBE 43). Every hour, the CTD was lowered to just above the bottom at our current location and recorded continuous vertical profiles of conductivity, temperature, pressure, and dissolved oxygen.

\section{Passive monitoring}

We took advantage of a regional consortium of researchers (Puget Sound Acoustic Telemetry Group) and an online acoustic detections database (HYDRA: http://hydra.sounddatamanagement.com/) in order to expand our monitoring of tagged jellyfish. Most relevant to our research was an array of receivers (Vemco ${ }^{\odot}$ VR2s and VR2Ws) deployed in lower Hood Canal by the University of Washington (Fig. 1). This array consisted of 38 receivers deployed within 2 rectangles at the north and south ends of lower Hood Canal; we supplemented this array by deploying 4 VR2Ws within the Great Bend of Hood Canal (Fig. 1). Receivers were deployed prior to all tagging efforts, so that movement of jellyfish could be detected from the time they were tagged. Deployed receivers continuously 'listened' for tags and recorded the date and time, identification code, and depth for each tag detection. All receivers within Hood Canal were recovered and data downloaded at the end of September 2010. Receivers elsewhere in Puget Sound were recovered and data entered into the online database at various time intervals, with all data from receivers in the water from 23 June to 30 September 2010 being available by March 2011. Range testing for V9P-1L tags at receiver sites within the Hood Canal array showed a $50 \%$ detection probability at a radius of $245 \mathrm{~m}$ (max range of detection $=420 \mathrm{~m}$; A. Beaudreau unpubl. data).

Long-term water quality data were obtained from the University of Washington, from their Oceanic Remote Chemical Analyzer (ORCA) buoy stationed in Hood Canal near our tagging site (Fig. 1). The ORCA buoy's automated sampler recorded continuous vertical profiles of temperature, salinity, dissolved oxygen, and other variables every $2 \mathrm{~h}$, from the surface to $120 \mathrm{~m}$ depth (see www.hoodcanal. washington.edu/observations/orca_buoy.jsp).

\section{Data analysis}

Prior to all analyses, data were filtered for quality control purposes. First, tags that obviously moved to the bottom and remained there for the duration of the study (e.g. due to tag shedding or jellyfish mortality) were removed. These were easily identified because they remained within the detection range of a re- 
ceiver throughout the study, and their depth patterns fluctuated around a fixed depth in time and magnitude consistent with tidal period and amplitude. Second, we removed data from the passive monitoring dataset if there were $<3$ detections for a jellyfish on a given date, receiver, day/night period, and tidal stage (ebb, flood, or slack). This reduced the probability of using false detections. All subsequent data analyses were performed in the statistical software package R (V2.11.1, R Core Development Team 2009) unless otherwise specified.

Vertical patterns of movement

At the small spatio-temporal scale, we used the depth data collected by the fixed VR2Ws for the 7 and 21 July active tracking sessions to evaluate the vertical movement of jellyfish because the amount of data collected by VR2Ws was much greater than data collected with the vessel-based receivers during active tracking. This was due to moving the boat in and out of range of individuals in order to re-locate all individuals each half hour, while most jellyfish remained within range of at least one of the VR2Ws for most of the duration of the active tracking sessions. For the tracking session on 23 June, the VR100 and VR28 data were used, as VR2Ws had not been deployed. Detections were categorized into day or night, depending on the time of sunset and sunrise. To account for individual variation, depth data for each jellyfish were normalized by subtracting the mean depth for that jellyfish from each detection depth and dividing by the standard deviation of the depths for that individual. We then used all depth detections as the dependent variable in a linear mixed model (LMM; PROC MIXED, SAS 2004) in which individual jellyfish were subjects upon which we made repeated measures. Because the detections of jellyfish depth were not independent observations and were unequally spaced in time, we used the spatial power covariance structure (sp[pow] in SAS) to account for temporal autocorrelation of the depth data. Using the sp(pow) covariance structure for unequally spaced time-series data provides a direct generalization of the autoregressive covariance structure generally used for equally spaced timeseries data (Littell et al. 1996). Diel period was our only fixed effect. We analyzed each species with separate LMMs. Assumptions of normality were verified through visual analysis of the residuals.

We also qualitatively compared the distribution of jellyfish depths with the depth of the pycnocline, which was determined using data collected from the CTD casts performed during tracking, to examine whether the jellyfish exhibited depth preferences based on environmental parameters.

To examine how each jellyfish species used the water column over a broader spatio-temporal scale, we repeated the LMMs described above using the normalized depths detected by the large-scale passive monitoring array as the dependent variable. In addition to diel period, we categorized depth detections into tidal stage (ebb, flood, slack after ebb [SE], slack after flood [SF]) according to predictions of currents at the ORCA buoy (Fig. 1). Tidal currents $<0.01 \mathrm{~m} \mathrm{~s}^{-1}$ were considered 'slack'. Diel period, tidal stage, and their interaction were fixed effects in the LMM.

Water quality data collected by the nearby ORCA buoy (Fig. 1) were used in place of CTD data to qualitatively compare long-term vertical movement patterns to the variation in the pycnocline and hypoxic layer over the duration of the study.

\section{Horizontal patterns of movement}

During active tracking, each individual was located approximately every half hour, typically with multiple detections when the boat was near the individual. We selected the strongest detection for each individual approximately every $30 \mathrm{~min}$ based on which detection had the lowest gain $(\mathrm{dB})$ and the strongest signal $(\mathrm{dB})$. We used the position of the boat to approximate the location of the jellyfish. Then we calculated the distance each jellyfish moved every $30 \mathrm{~min}$ to estimate horizontal rates of movement. If net movement was to the south, this rate of movement received a negative value. Depth-specific current velocities for our study site and time period were forecast from a tidal current prediction model (see the supplement at www.int-res.com/articles/ suppl/m455p001_supp.pdf for a description and validation of the model). This provided current estimates at $1 \mathrm{~m}$ depth intervals in the water column every $5 \mathrm{~min}$, which we averaged over 30 min intervals. Again, currents flowing in a northern direction received positive values, while those flowing in a southern direction received negative values. We calculated the average depth for each individual for each 30 min interval; these were rounded to the nearest meter. Then, for each 30 min interval we subtracted the mean current velocity at the mean depth of the jellyfish from the estimated horizontal rate of movement for that $30 \mathrm{~min}$ period. Swimming rates 
were not calculated when the average jellyfish depth was shallower than $6 \mathrm{~m}$ or deeper than $100 \mathrm{~m}$, due to relatively high uncertainty in the modeled current velocities at these extreme depths (see the supplement). A horizontal swimming speed of $0 \mathrm{~m} \mathrm{~s}^{-1}$ indicates no active swimming occurred (i.e. the jellyfish simply moved at the same speed as the tidal current), while a positive rate indicates that the jellyfish was swimming north and a negative rate indicates swimming in a southern direction. Horizontal swimming speeds were classified according to diel period and tidal stage. Currents $<0.01 \mathrm{~m} \mathrm{~s}^{-1}$ were classified as slack tides. For lion's mane jellyfish, we used the horizontal swimming speed as the dependent variable in 2 separate linear models with diel period or tidal stage as the predictor variable. Due to correlations between diel period and tidal stage over the 3 tracking periods (i.e. the strongest ebb tide was near dawn during each of our active tracking sessions), diel period and tidal stage were not combined into a single model. As a correction for using 2 univariate tests, we used $\alpha=0.025$ to evaluate significant results for small-scale horizontal movement.

At the scale of Hood Canal, each passive receiver location was given a north/south value that corresponded to the distance $(\mathrm{km})$ it was from the most northerly receiver in the southern rectangle (Fig. 1). This provided a coarse measure of north/south dispersal of each jellyfish over the course of the summer. The movement of jellyfish was qualitatively summarized with distance profiles by plotting the last recorded position of each jellyfish. Net displacement rates were calculated by dividing net displacement by number of days tracked. For lion's mane jellyfish, net displacement rates were compared using an analysis of variance (ANOVA) with tagging group as the factor. Cumulative distances traveled were calculated for each jellyfish by summing the total distance moved.

\section{RESULTS}

We tagged 10, 5, 14, and 1 jellyfish during each tagging session, respectively (Table 1). Of these tagged individuals, we were able to actively track 14 lion's mane and 4 fried-egg jellyfish for $24 \mathrm{~h}$, while we were able to collect data for 3 to $15 \mathrm{~d}$ on 10 lion's mane and 4 fried-egg jellyfish. The fate of the remaining tagged individuals is unknown, but they likely either shed their tags, died following tagging, or moved out of detection range soon after tagging and were not detected again.

Table 1. Cyanea capillata and Phacellophora camtschatica. Tagging, biological, and movement information for jellyfish tagged with acoustic transmitters in Hood Canal, Washington, USA, in 2010. Net displacement: distance moved from tagging site to last detection (negative values denote net southerly movement; positive values denote net northerly movement). Cumulative displacement: summed distance of all horizontal movements

\begin{tabular}{|c|c|c|c|c|c|}
\hline ID & $\begin{array}{l}\text { Tagging } \\
\text { date } \\
(\mathrm{mo} / \mathrm{d})\end{array}$ & $\begin{array}{c}\text { Bell } \\
\text { diameter } \\
(\mathrm{cm})\end{array}$ & $\begin{array}{c}\text { Passive } \\
\text { tracking } \\
\text { duration }(\mathrm{d})\end{array}$ & $\begin{array}{c}\text { Net } \\
\text { displacement } \\
(\mathrm{km})\end{array}$ & $\begin{array}{c}\text { Cumulative } \\
\text { displacement } \\
(\mathrm{km})\end{array}$ \\
\hline \multicolumn{6}{|c|}{ C. capillata } \\
\hline $64^{\mathrm{a}, \mathrm{b}}$ & $6 / 23$ & 35 & 7 & -7.2 & 40.5 \\
\hline 65 & $6 / 23$ & 25 & 1 & - & - \\
\hline 66 & $6 / 23$ & 20 & 2 & - & - \\
\hline $67^{a, b}$ & $6 / 23$ & 25 & 4 & -5.0 & 23.5 \\
\hline $68^{\mathrm{a}}$ & $6 / 23$ & 20 & 2 & - & - \\
\hline $69^{a}$ & $6 / 23$ & 20 & 2 & - & - \\
\hline $70^{a, b}$ & $6 / 23$ & 25 & 7 & -7.2 & 27.4 \\
\hline $71^{a, b}$ & $6 / 23$ & 20 & 3 & -3.1 & 10.0 \\
\hline $72^{\mathrm{a}, \mathrm{b}}$ & $6 / 23$ & 25 & 3 & -7.2 & 7.2 \\
\hline $197^{\mathrm{a}, \mathrm{b}}$ & $6 / 23$ & 30 & 6 & -7.2 & 17.9 \\
\hline $200^{\mathrm{a}}$ & $7 / 7$ & 25 & 2 & - & - \\
\hline $202^{\mathrm{a}}$ & $7 / 7$ & 35 & 2 & - & - \\
\hline $203^{a, b}$ & $7 / 7$ & 25 & 15 & -7.2 & 39.8 \\
\hline $205^{a, b}$ & $7 / 7$ & 30 & 15 & -3.1 & 38.7 \\
\hline $206^{a, b}$ & $7 / 7$ & 30 & 9 & 2.6 & 32.0 \\
\hline $40^{\mathrm{a}, \mathrm{b}}$ & $7 / 21$ & 25 & 6 & -7.2 & 16.5 \\
\hline 208 & $7 / 21$ & 25 & 1 & - & - \\
\hline \multicolumn{6}{|c|}{ P. camtschatica } \\
\hline 41 & $7 / 21$ & 25 & 2 & - & - \\
\hline $43^{a, b}$ & $7 / 21$ & 30 & 13 & -7.2 & 50.4 \\
\hline $44^{\mathrm{a}, \mathrm{b}}$ & $7 / 21$ & 45 & 14 & 2.6 & 23.8 \\
\hline 45 & $7 / 21$ & 30 & 2 & - & - \\
\hline $198^{a, b}$ & $7 / 21$ & 40 & 5 & 2.6 & 6.9 \\
\hline $199^{a, b}$ & $7 / 21$ & 40 & 3 & -3.1 & 3.2 \\
\hline 201 & $7 / 21$ & 25 & 1 & - & - \\
\hline 204 & $7 / 21$ & 25 & 2 & - & - \\
\hline 207 & $7 / 21$ & 25 & 1 & - & - \\
\hline 209 & $7 / 21$ & 25 & 2 & - & - \\
\hline 210 & $7 / 21$ & 35 & 0 & - & - \\
\hline 211 & $7 / 21$ & 25 & 1 & - & - \\
\hline 52 & $8 / 12$ & 35 & 1 & - & - \\
\hline
\end{tabular}




\section{Vertical patterns of movement}

\section{Small spatio-temporal scale}

Individual variation in vertical profiles was high over the small spatio-temporal scale. Multiple patterns of movement were observed, with some jellyfish staying at a relatively shallow, constant depth for the $24 \mathrm{~h}$ period, others making continuous small 'bounces' up and down, and others making multiple large dives (Fig. 2). Individual jellyfish generally resided below the pycnocline, and had a tendency to avoid crossing this boundary layer. There were no diel differences in mean depth for lion's mane or fried egg jellyfish over this time period (lion's mane: $F_{1,13}=$ 0.04, $\mathrm{p}=0.854$; fried-egg: $F_{1,3}=14.84, \mathrm{p}=0.126$ ).

\section{Large spatio-temporal scale}

Both species of jellyfish were detected by the large-scale passive receiver array at depths ranging from near the surface to $>100 \mathrm{~m}$, for periods of up to $15 \mathrm{~d}$ (Table 1). Long-term monitoring confirmed short-term observations that variation in vertical movement was high both within and among individuals (Fig. 3). Moreover, jellyfish tended to stay below the pycnocline, which was consistent with short-term observations (Fig. 4). Jellyfish made numerous dives into the hypoxic layer $\left(<2 \mathrm{mg} \mathrm{O}_{2} \mathrm{l}^{-1}\right)$, which occurred at a mean $\pm \mathrm{SE}$ depth of $74.6 \pm 1.29 \mathrm{~m}$ over the duration of the study.

Lion's mane jellyfish used deeper waters during the day than during the night $\left(F_{1,10}=9.19 ; \mathrm{p}=0.013\right)$, but we found no differences in depth among tidal stages $\left(F_{3,30}=1.05 ; \mathrm{p}=0.385\right)$, nor a significant interaction between diel period and tidal stage $\left(F_{3,25}=\right.$ $0.09 ; \mathrm{p}=0.968)$. The difference in mean depth between day and night for individual jellyfish ranged from 0.1 to $32 \mathrm{~m}$ (mean: $10.5 \pm 3.4 \mathrm{~m}$ ). For fried-egg jellyfish, we found no significant differences in mean depth for diel period $\left(F_{1,3}=2.66 ; \mathrm{p}=0.201\right)$, tidal stage $\left(F_{3,9}=2.30 ; \mathrm{p}=0.146\right)$ or their interaction $\left(F_{3,9}=\right.$ $3.68 ; \mathrm{p}=0.056)$.

\section{Horizontal patterns of movement}

Small spatio-temporal scale

Horizontal swimming speeds varied with diel pe$\operatorname{riod}\left(F_{1,142}=4.95, \mathrm{p}=0.028\right)$ and tidal period for lion's mane jellyfish (Fig. 5, $F_{3,135}=7.05, \mathrm{p}<0.001$ ). They

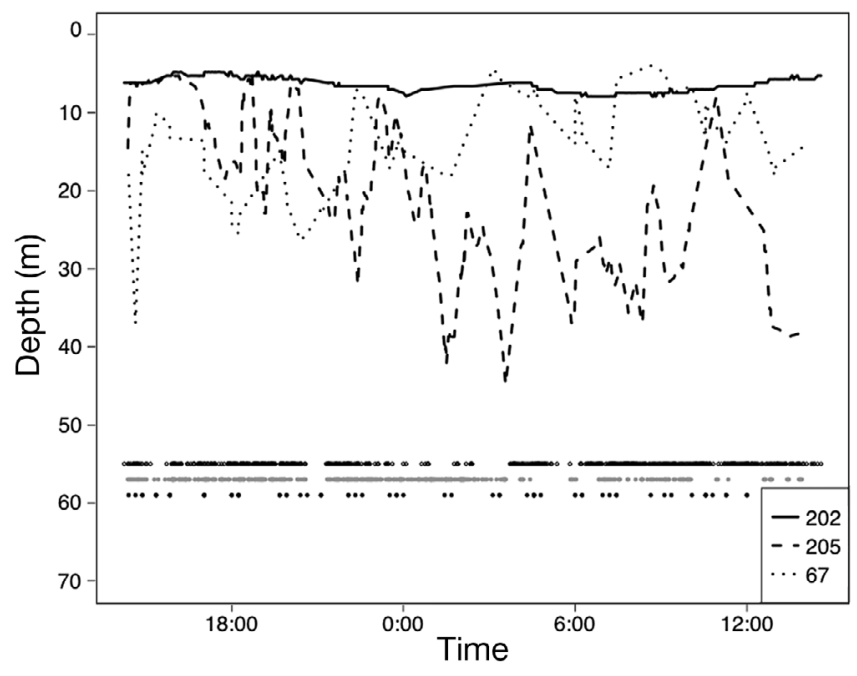

Fig. 2. Cyanea capillata. Example of 3 individual tracks of lion's mane jellyfish from receivers during $24 \mathrm{~h}$ active tracking sessions. The small circles at the bottom indicate detections; open circles (upper row) correspond to detections for jellyfish 202, gray circles (middle row) to 205 and black circles (lower row) to 67

swam faster at night than during the day, with a mean speed of $5.70 \pm 0.87 \mathrm{~cm} \mathrm{~s}^{-1}$ compared to $1.96 \pm$ $0.52 \mathrm{~cm} \mathrm{~s}^{-1}$ during the day. Among tidal stages, their swimming speed was fastest in flood tides, when jellyfish swam at $5.24 \pm 0.70 \mathrm{~cm} \mathrm{~s}^{-1}$ in a northern direction against incoming tides. Similarly, fried-egg jellyfish swimming speeds varied with both diel period $\left(F_{1,58}=9.02, \mathrm{p}=0.004\right)$ and tidal stage (Fig. $5, F_{3,56}=$ 10.52, $\mathrm{p}<0.001)$ as well. In contrast to lion's mane

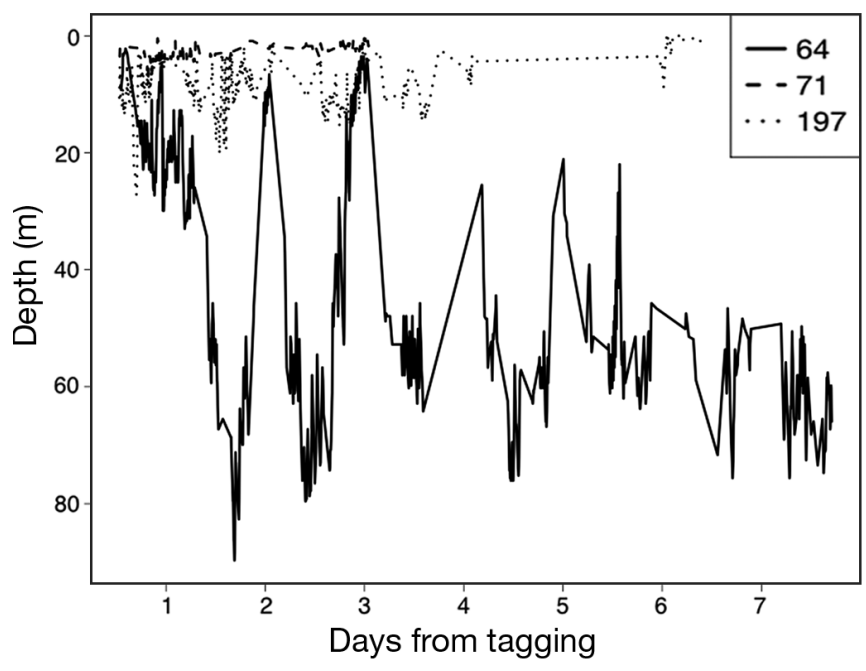

Fig. 3. Cyanea capillata. Example tracks of vertical movement for individual lion's-mane jellyfish over the duration of time they were detected by passive acoustic receivers 


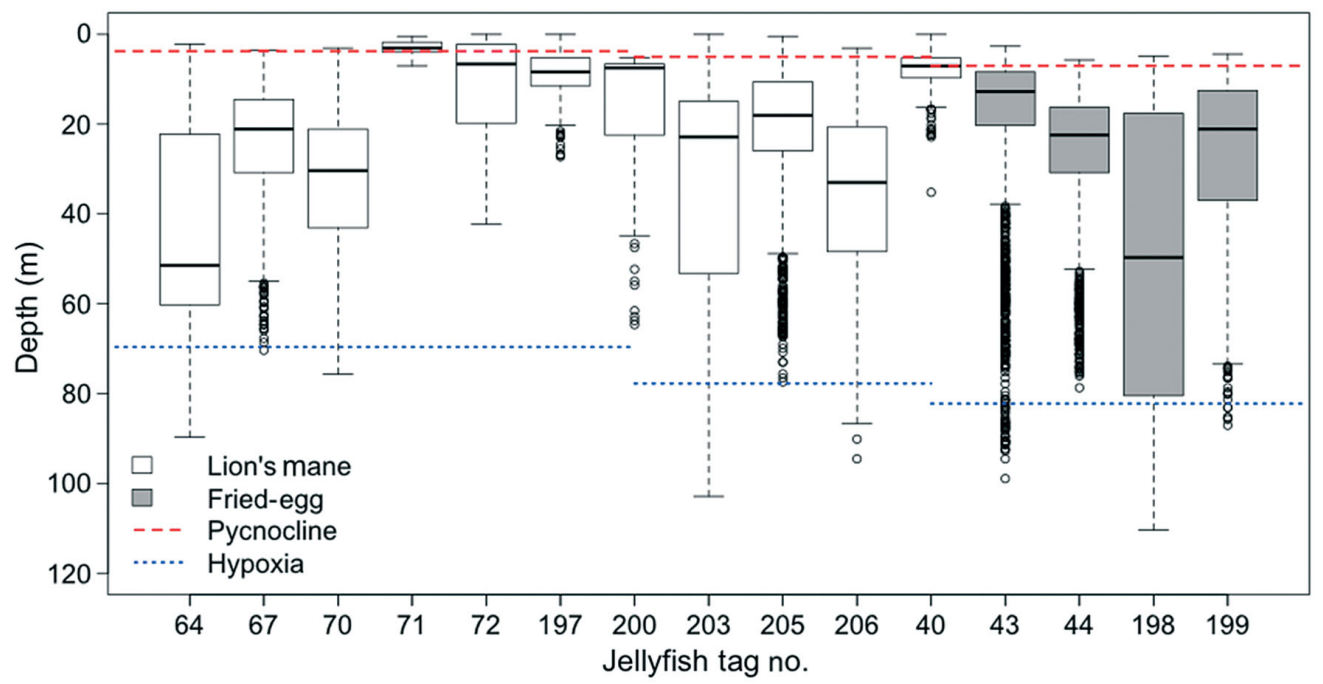

Fig. 4. Cyanea capillata and Phacellophora camtschatica. Distribution of depths of tagged jellyfish during passive tracking in relation to the pycnocline and hypoxic water layers. Horizontal lines inside boxes are median depth values. Boxes represent the 25th and 75th percentiles, while whiskers are the 5th and 95th percentiles, and individual points are outliers

jellyfish, fried-egg jellyfish moved faster during the day, averaging $7.87 \pm 1.15 \mathrm{~cm} \mathrm{~s}^{-1}$, compared to $3.33 \pm$ $0.68 \mathrm{~cm} \mathrm{~s}^{-1}$ at night. However, similar to lion's mane jellyfish, fried-egg jellyfish swam fastest during flood tides, averaging $10.2 \pm 1.10 \mathrm{~cm} \mathrm{~s}^{-1}$. For both species, mean swimming rates for all diel periods and tidal stages were positive or 0 , indicating active swimming in a northern direction.

\section{Large spatio-temporal scale}

All detections of jellyfish occurred within the rectangular array of 20 receivers in southern Hood Canal (Fig. 1); no jellyfish were detected anywhere else in Hood Canal or the greater Puget Sound region. All but one lion's mane jellyfish displayed net southern dispersal through Hood Canal (Table 1; Fig. 6a), and the one individual (ID 206) that was north of its tagging location at last detection appeared to be showing a movement pattern similar to 2 other jellyfish in the same tagging group who later moved south (IDs 203 and 205). Thus, net displacement for lion's mane jellyfish was further into Hood Canal and did not differ among tagging groups (Table $1, F_{2,7}=1.67, \mathrm{p}=0.256$; mean displacement rate $=0.95 \pm 0.23 \mathrm{~km} \mathrm{~d}^{-1}$ to the south, Fig. 6a). Friedegg jellyfish moved at a slower, more variable rate in a southern direction as well (mean $=0.22 \pm 0.35 \mathrm{~km}$ $\mathrm{d}^{-1}$ to the south, Fig. $6 \mathrm{~b}$ ). Cumulative distances traveled ranged from 7.2 to $40.5 \mathrm{~km}$ for lion's mane jellyfish and 3.2 to $50.4 \mathrm{~km}$ for fried-egg jellyfish.

\section{DISCUSSION}

Our study builds upon a growing literature demonstrating the power of acoustic telemetry in tracking marine animal movements and identifying individual differences in behavior in relation to environmental cues (e.g. Heithaus et al. 2002, Andrews et al. 2009, Tolimieri et al. 2009). In particular, we demonstrated

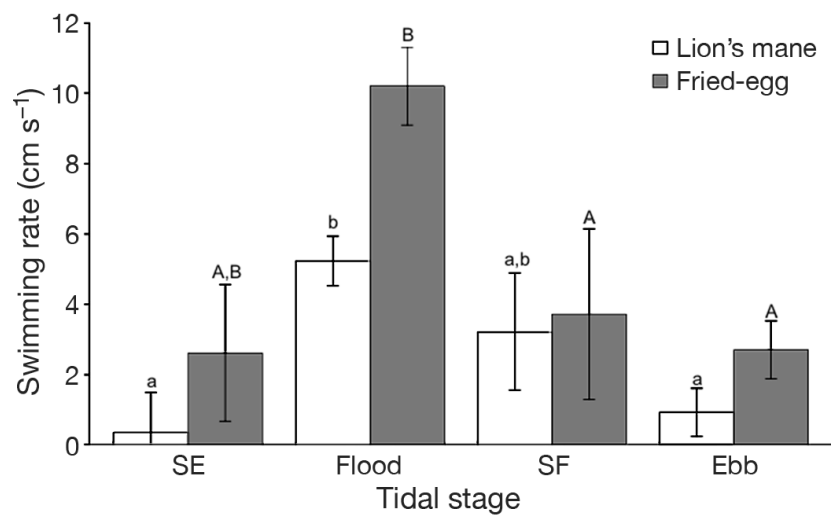

Fig. 5. Cyanea capillata and Phacellophora camtschatica. Mean swimming rates for lion's mane $\left(F_{3,135}=7.05, \mathrm{p}<\right.$ $0.001)$ and fried-egg $\left(F_{3,56}=10.52, \mathrm{p}<0.001\right)$ jellyfish varied by tidal stage. Positive rates indicated a northern swimming direction, out of Hood Canal, while negative rates indicate a southern swimming direction, into Hood Canal. During flood tides, current direction was south, and during ebb tides, currents flowed north. Letters above bars indicate significant differences from bars with different letters for that species (Tukey test, $\mathrm{p}<0.05$ ). SE: slack after ebb; SF: slack after flood. Error bars $=\mathrm{SE}$ 

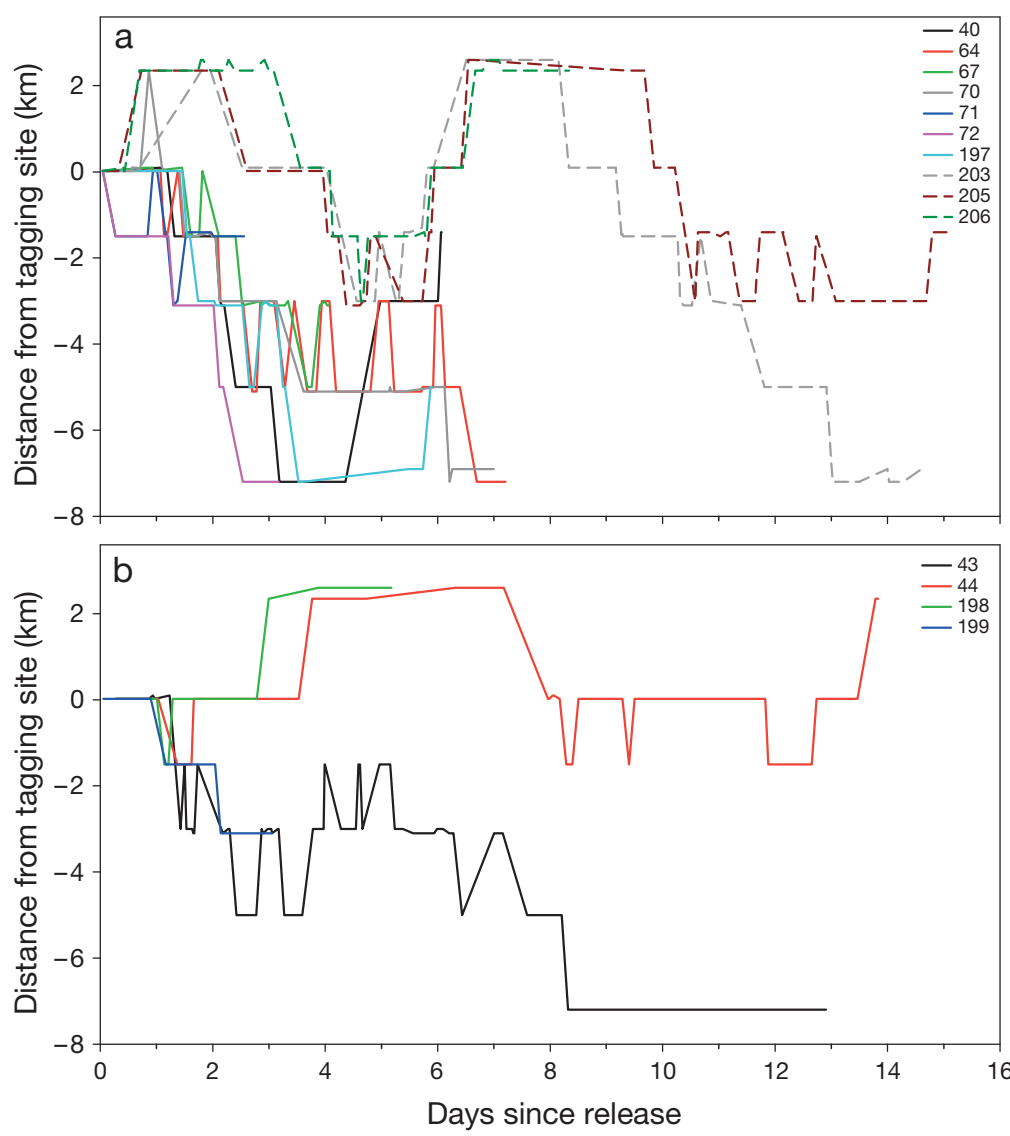

Fig. 6. Cyanea capillata and Phacellophora camtschatica. Spatial movement of individual (a) C. capillata (solid colored lines tagged 23 June, dashed lines tagged 7 July, and solid black line tagged 21 July 2010) and (b) P. camtschatica jellyfish over the duration of the time they were detected by passive acoustic receivers

the improving capacity of techniques to track movements of soft-bodied invertebrates, following upon recent published work by other groups (Hays et al. 2008, 2012, Gordon \& Seymour 2009). We characterized movement behaviors of 2 scyphozoan jellyfish species on multiple spatio-temporal scales by using a combination of active and passive tracking with acoustic telemetry. As with other recent studies of jellyfish movement (e.g. Kaartvedt et al. 2011, Hays et al. 2012), we observed some generalizable behaviors in the species we observed, but also a high degree of individual variation. Several more specific patterns in jellyfish behavior also emerged, which we outline briefly below.

In the longer-term data, lion's mane jellyfish moved to shallower depths at night, while fried-egg jellyfish did not. Previous studies on other jellyfish species also reported mixed results with some jellyfish species performing diel vertical migrations (Graham et al. 2001) and other species not performing these migrations (Hays et al. 2012). Jellyfish may perform these diel vertical migrations to maintain a range of preferred absolute light intensities (Dupont et al. 2009) or to follow food resources, such as zoplankton (Spadinger \& Maier 1999, Mutlu 2006). Potential jellyfish prey such as calanoid copepods and euphausiids undergo pronounced diel vertical migrations in Hood Canal (Bollens et al. 1992, Parker-Stetter et al. 2009). However, as discussed by Hays et al. (2012), differences in predation strategies may exist between species, which could lead to differences in these vertical migrations. The presence of diel vertical migrations in fried-egg jellyfish may not have emerged in the small spatiotemporal data due to the high individual variation and the small sample size.

Additionally, most jellyfish appeared to avoid crossing the pycnocline, which was highly correlated with both the thermocline and the halocline in our study area. In both the small and large spatiotemporal data, most individuals remained primarily below the pycnocline, with only a few individuals commonly crossing the barrier. Those jellyfish that were observed above the pycnocline or crossing it in the small spatio-temporal data were also the individuals that crossed it most often in the large spatio-temporal data. Why most jellyfish did not cross the density gradient is unclear. The sizes of the medusae we tagged would have allowed them to easily swim through the density gradient, but they may have avoided doing so in order to maintain the osmotic conditions to which they had acclimated (Graham et al. 2001). Although jellyfish respiration rates are apparently not temperature-dependent (Purcell et al. 2010), pulsation rates may decrease below the thermocline due to the cooler temperature (Dillon 1977), which may result in lower energy requirements.

Several deep-diving individuals, representing both species, made regular excursions lasting up to several hours into the deep hypoxic zone. This is consistent with a previous experimental study, in which both species were found to have critical oxygen minima $<2.0 \mathrm{mg} \mathrm{l}^{-1}$ and both were capable of surviving in hypoxic water for hours (Rutherford \& Thuesen 2005). It has been hypothesized that increasing hypoxia in coastal habitats will give jellyfish a competitive advantage over fish, as jellyfish are more tol- 
erant to low dissolved oxygen levels (Richardson et al. 2009). They will thus be able to use the entire water column and take advantage of pelagic prey resources that hypoxia-intolerant fishes cannot (Breitburg et al. 1997, Brodeur et al. 2008). This may indeed be the case in Hood Canal, where some zooplanktivorous fish have been shown to avoid severely hypoxic water (Parker-Stetter et al. 2009). In waters of coastal Japan, predation rates upon fish larvae by moon jellyfish Aurelia aurita were greater in hypoxic water than in normoxic water (Shoji et al. 2005). Additionally, Shoji et al. (2010) reported that abundance of moon jellyfish increased in bottom waters with low dissolved oxygen levels. If hypoxic summer conditions in Hood Canal continue to grow more frequent and extensive as predicted (Essington \& Paulsen 2010), we would anticipate an interaction between dissolved oxygen conditions and the foraging success of hypoxia-tolerant jellyfish compared to zooplanktivorous fishes such as Pacific hake Merluccius productus and Pacific herring Clupea pallasii.

The horizontal movement rates from the active tracking data suggest that jellyfish typically swim towards the mouth of Hood Canal during flood tides. While jellyfish exhibited net southern diffusion over longer time periods, they appear to actively swim to avoid this pattern. As southern Hood Canal often contains large jellyfish aggregations, avoiding southern dispersion may decrease competition for food resources and preferred habitat. Whatever the reason for these movement patterns, it is clear that these jellyfish were not simply passively planktonic, but exhibited active swimming behaviors that influenced their lateral distribution, as has also been suggested by Doyle et al. (2007).

The adaptive advantages of accumulation of jellyfish and other gelatinous zooplankton have generally been related to foraging opportunities and sexual reproduction (reviewed by Hamner \& Dawson 2009). Regardless, this southern net movement suggests that the southern part of Hood Canal is a sink for jellyfish, in which case the ecological effects of jellyfish in Hood Canal may be stronger than otherwise expected. This may lead to increased pressure on fish and other taxa, including commercially and ecologically important species. However, there were some individual jellyfish that either displayed net dispersal north, or remained in the same approximate area as tagging, providing further evidence for individual variation in movements.

Our methods allowed for data to be collected on jellyfish behavior for periods up to $15 \mathrm{~d}$, enabling us to evaluate individual behavior over a range of phys- ical conditions, multiple tidal exchanges, and multiple diel cycles. The large-scale spatio-temporal data showed patterns not present in the small-scale spatio-temporal tracking and provided information on dispersal patterns. The longer tracks most clearly demonstrated the high degree of individual variation in depth distribution, as well as the net displacement over a series of consecutive tidal cycles. Furthermore, our large-scale spatio-temporal data support the hypothesis that individual scyphozoan jellyfish movements are consistent with Lévy flights (Hays et al. 2012), wherein short movements or depth changes are occasionally interspersed with longer relocation movements, possibly as a means of utilizing dispersed and patchy prey fields. For example, lion's mane jellyfish ID 64 alternated between frequent, relatively small changes in depth and pronounced ascents or dives of $>40 \mathrm{~m}$ (Fig. 3). Notably, the water column in the study by Hays et al. (2012) was much shallower (maximum depth $\sim 10 \mathrm{~m}$ ) than at our study area, and thus Hays et al. (2012) were unable to determine whether Lévy flight behavior of the scyphozoan Rhizostoma octopus was affected by diel vertical migration behavior. As we observed evidence of diel vertical migration and potential Lévy flight in some of our longer tracks of lion's mane jellyfish, future work at this location with improved sample sizes and long passive tracking periods may help resolve the relative importance of Lévy search behavior and diel vertical migration.

Additionally, the passive tracking method was much less labor intensive than active tracking. Future jellyfish tracking studies may benefit most from devoting resources to increasing the total number of tagged individuals and then tracking them passively, with a well-placed array of receivers, and devoting fewer resources to active tracking unless the focal questions call for fine-scale understanding of jellyfish location in 3-dimensional space. Future studies would also benefit greatly from improved tagging efficiency. Our success rate for tracking individual jellyfish for at least $72 \mathrm{~h}$ was $59 \%$ for lion's mane jellyfish and $31 \%$ for fried-egg jellyfish, and most of the apparently unsuccessful tagging attempts involved individuals with bell diameters $\leq 30 \mathrm{~cm}$ (Table 1). Increasing minimum tagging sizes may increase success rates in the future. Further improvements in acoustic tag technology, such as lighter tags with sensor capabilities and comparable signal strength and battery life, and in methods for physically attaching tags to soft-bodied active organisms such as jellyfish will also improve overall data yield. 


\section{CONCLUSION}

Jellyfish aggregations are an important component of many coastal marine ecosystems (Purcell et al. 2007, Richardson et al. 2009, Condon et al. 2012), and are a major component of the pelagic biomass of Puget Sound (Rice 2007). It is premature to draw conclusions about their functional importance in Puget Sound, given how little we know about their populations and ecology in this region (Essington et al. 2011). However, the use of acoustic telemetry in this study provided us with both short-term and longterm data on the behavior of individual jellyfish. We found that some jellyfish in Hood Canal undergo diel vertical migrations that may span most of the water column; that they can maintain lateral position despite tidal exchanges; and that they can withstand hypoxic conditions at least for many hours. Although we have only limited temporal coverage, we also have indication that this portion of Hood Canal is a jellyfish sink, rather than a source of jellyfish to other basins of Puget Sound. This study provides an important behavioral context in which to further examine interactions between jellyfish and other species.

Acknowledgements. We thank members of the Ecosystem Science Program (G. Williams, N. Tolimieri, J. Samhouri) at the Northwest Fisheries Science Center (NWFSC) for helping with the collection, tagging, and active tracking of jellyfish. T. Essington, A. Beaudreau, H. Nelson, N. Grose, and F. Stevick deployed and retrieved acoustic receivers in Hood Canal. M. Gordon, G. Hays, R. Brodeur, E. Thuesen, and S. Parker-Stetter provided helpful discussion regarding collecting and tagging jellyfish. We thank the ORCA project for data used in calculating the pycnocline and depth of hypoxia. ORCA data were provided by A. Devol and W. Ruef, and funded primarily by the US Navy, NOAA, and NSF. This work was funded by a scholarship from NOAA's Ernest F. Hollings Scholar Program (to P.E.M.) and an internal grant from the NWFSC (to C.J.H. and K.S.A.). We also thank M.L.V. Ciccone for inspiration during active tracking sessions.

\section{LITERATURE CITED}

Albert DJ (2007) Aurelia labiata medusae (Scyphozoa) in Roscoe Bay avoid tidal dispersion by vertical migration. J Sea Res 57:281-287

> Andrews KS, Williams GD, Farrer D, Tolimieri N, Harvey CJ, Bargmann G, Levin PS (2009) Diel activity patterns of sixgill sharks, Hexanchus griseus: the ups and downs of an apex predator. Anim Behav 78:525-536

> Andrews KS, Williams GD, Levin PS (2010) Seasonal and ontogenetic changes in movement patterns of sixgill sharks. PLoS ONE 5:e12549

Babson AL, Kawase M, MacCready P (2006) Seasonal and interannual variability in the circulation of Puget Sound, Washington: a box model study. Atmos-Ocean 44:29-45
Bamstedt U, Kaartvedt S, Youngbluth M (2003) An evaluation of acoustic and video methods to estimate the abundance and vertical distribution of jellyfish. J Plankton Res 25:1307-1318

> Barnett A, Abrantes KG, Stevens JD, Bruce BD, Semmens JM (2010) Fine-scale movements of the broadnose sevengill shark and its main prey, the gummy shark. PLoS ONE 5:e15464

> Bastian T, Haberlin D, Purcell JE, Hays GC, Davenport J, McAllen R, Doyle TK (2011) Large-scale sampling reveals the spatio-temporal distributions of the jellyfish Aurelia aurita and Cyanea capillata in the Irish Sea. Mar Biol 158:2639-2652

Baumgartner MF, Mate BR (2005) Summer and fall habitat of North Atlantic right whales (Eubalaena glacialis) inferred from satellite telemetry. Can J Fish Aquat Sci 62:527-543

Bollens SM, Frost BW, Lin TS (1992) Recruitment, growth, and diel vertical migration of Euphausia pacifica in a temperate fjord. Mar Biol 114:219-228

Breitburg DL, Loher T, Pacey CA, Gerstein A (1997) Varying effects of low dissolved oxygen on trophic interactions in an estuarine food web. Ecol Monogr 67:489-507

Brodeur RD, Suchman CL, Reese DC, Miller TW, Daly EA (2008) Spatial overlap and trophic interactions between pelagic fish and large jellyfish in the northern California Current. Mar Biol 154:649-659

> Condon RH, Steinberg DK, del Giorgio PA, Bouvier TC, Bronk DA, Graham WM, Ducklow HW (2011) Jellyfish blooms result in a major microbial respiratory sink of carbon in marine systems. Proc Natl Acad Sci USA 108: 10225-10230

> Condon RH, Graham WM, Duarte CM, Pitt KA and others (2012) Questioning the rise of gelatinous zooplankton in the world's oceans. Bioscience 62:160-169

Dillon TM (1977) Effects of acute changes in temperature and salinity on pulsation rates in ephyrae of the scyphozoan Aurelia aurita. Mar Biol 42:31-35

Doyle TK, Houghton JDR, Buckley SM, Hays GC, Davenport J (2007) The broad-scale distribution of five jellyfish species across a temperate coastal environment. Hydrobiologia 579:29-39

> Dupont N, Klevjer TA, Kaartvedt S, Aksnes DL (2009) Diel vertical migration of the deep-water jellyfish Periphyllya periphylla simulated as individual responses to absolute light intensity. Limnol Oceanogr 54:1765-1775

> Essington TE, Paulsen CE (2010) Quantifying hypoxia impacts on an estuarine demersal community using a hierarchical ensemble approach. Ecosystems 13: 1035-1048

Essington TE, Klinger T, Conway-Cranos T, Buchanan J and others (2011) The biophysical condition of Puget Sound. In: Puget Sound science update, April 2011 version. Puget Sound Partnership, Tacoma, WA, p 205-423 Available at www.psp.wa.gov/ (accessed 1 June 2011)

Gillanders B (2005) Otolith chemistry to determine movements of diadromous and freshwater fish. Aquat Living Resour 18:291-300

Glover DC, Dettmers JM, Wahl DH, Clapp DF (2008) Yellow perch (Perca flavescens) stock structure in Lake Michigan: an analysis using mark-recapture data. Can J Fish Aquat Sci 65:1919-1930

Gordon MR, Seymour JE (2009) Quantifying movement of the tropical Australian cubozoan Chironex fleckeri using acoustic telemetry. Hydrobiologia 616:87-97 
Graham WM, Pages F, Hamner WM (2001) A physical context for gelatinous zooplankton aggregations: a review. Hydrobiologia 451:199-212

Hamner WM, Dawson MN (2009) A review and synthesis on the systematics and evolution of jellyfish blooms: advantageous aggregations and adaptive assemblages. Hydrobiologia 616:161-191

- Hays GC, Doyle TK, Houghton JDR, Lilley MKS, Metcalfe JD, Righton D (2008) Diving behavior of jellyfish equipped with electronic tags. J Plankton Res 30:325-331

Hays GC, Bastian T, Doyle TK, Fossette S and others (2012) High activity and Lévy searches: Jellyfish can search the water column like fish. Proc Biol Sci 279:465-473

Heithaus MR, Dill LM, Marshall GJ, Buhleier B (2002) Habitat use and foraging behavior of tiger sharks (Galeocerdo cuvier) in a seagrass ecosystem. Mar Biol 140:237-248

Houghton JDR, Doyle TK, Davenport J, Hays GC (2006) Developing a simple, rapid method for identifying and monitoring jellyfish aggregations from the air. Mar Ecol Prog Ser 314:159-170

Hovel KA, Wahle RA (2010) Effects of habitat patchiness on American lobster movement across a gradient of predation risk and shelter competition. Ecology 91:1993-2002

Irving DB, Modde T (2000) Home-range fidelity and use of historic habitat by adult Colorado pikeminnow (Ptychocheilus lucius) in the White River, Colorado and Utah. West N Am Nat 60:16-25

Kaartvedt S, Klevjer TA, Torgersen T, Sornes TA, Rostad A (2007) Diel vertical migration of individual jellyfish (Periphylla periphylla). Limnol Oceanogr 52:975-983

Kaartvedt S, Titelman J, Røstad A, Klevjer TA (2011) Beyond the average: diverse individual migration patterns in a population of mesopelagic jellyfish. Limnol Oceanogr 56:2189-2199

Littell RC, Milliken GA, Stroup WW, Wolfinger RD (1996) SAS system for mixed models. SAS Institute Inc, Cary, $\mathrm{NC}$

MacKenzie K (2002) Parasites as biological tags in population studies of marine organisms: an update. Parasitology 124:S153-S163

- Mutlu E (2006) Diel vertical migration of Sagitta setosa as inferred acoustically in the Black Sea. Mar Biol 149: 573-584

Parker-Stetter SL, Horne JK (2009) Nekton distribution and midwater hypoxia: a seasonal, diel prey refuge? Estuar Coast Shelf Sci 81:13-18

Parker-Stetter SL, Horne JK, Langness MM (2009) The influence of midwater hypoxia on nekton vertical migration. ICES J Mar Sci 66:1296-1302

Pauly D, Graham W, Libralato S, Morissette L, Palomares MLD (2009) Jellyfish in ecosystems, online databases and ecosystem models. Hydrobiologia 616:67-85

Payne JC, Andrews KS, Chittenden CM, Crossin GT and others (2010) Tracking fish movements and survival on the Northeast Pacific Shelf. In: McIntyre AD (ed) Life in the world's oceans: distribution, diversity and abundance. Blackwell, Oxford, p 269-290

Editorial responsibility: Marsh Youngbluth,

Fort Pierce, Florida, USA
PSP (Puget Sound Partnership) (2008) Puget Sound action agenda: protecting and restoring the Puget Sound ecosystem by 2020. Puget Sound Partnership, Olympia, WA

> Purcell JE, Arai MN (2001) Interactions of pelagic cnidarians and ctenophores with fish: a review. Hydrobiologia 451: $27-44$

Purcell JE, Uye SI, Lo WT (2007) Anthropogenic causes of jellyfish blooms and their direct consequences for humans: a review. Mar Ecol Prog Ser 350:153-174

Purcell JE, Fuentes V, Atienza D, Tilves U, Astorga D, Kawahara M, Hays GC (2010) Use of respiration rates of scyphozoan jellyfish to estimate their effects on the food web. Hydrobiologia 645:135-152

R Core Development Team (2009) R: a language and environment for statistical computing. $\mathrm{R}$ Foundation for Statistical Computing, Vienna. Available at www.Rproject.org

Rice CA (2007) Evaluating the biological condition of Puget Sound. PhD dissertation, University of Washington, Seattle, WA

> Richardson AJ, Bakun A, Hays GC, Gibbons MJ (2009) The jellyfish joyride: causes, consequences and management responses to a more gelatinous future. Trends Ecol Evol 24:312-322

Rutherford LD Jr, Thuesen EV (2005) Metabolic performance and survival of medusae in estuarine hypoxia. Mar Ecol Prog Ser 294:189-200

Samhouri JF, Levin PS, Harvey CJ (2009) Quantitative evaluation of marine ecosystem indicator performance using food web models. Ecosystems 12:1283-1298

SAS (2004) SAS 9.1.3. SAS Institute Inc., Cary, NC

- Shoji J, Masuda R, Yamashita Y, Tanaka M (2005) Predation on fish larvae by moon jellyfish Aurelia aurita under low dissolved oxygen concentration. Fish Sci 71:748-753

- Shoji J, Kudoh T, Takatsuji H, Kawaguchi O, Kasai A (2010) Distribution of moon jellyfish Aurelia aurita in relation to summer hypoxia in Hiroshima Bay, Seto Inland Sea. Estuar Coast Shelf Sci 86:485-490

> Simpfendorfer CA, Wiley TR, Yeiser BG (2010) Improving conservation planning for an endangered sawfish using data from acoustic telemetry. Biol Conserv 143:1460-1469

Smith DR, Brousseau LJ, Mandt MT, Millard MJ (2010) Age and sex specific timing, frequency, and spatial distribution of horseshoe crab spawning in Delaware Bay: insights from a large-scale radio telemetry array. Curr Zool 56:563-574

Spadinger R, Maier G (1999) Prey selection and diel feeding of the freshwater jellyfish, Craspedacusta sowerbyi. Freshw Biol 41:567-573

Sutherland DA, MacCready P, Banas NS, Smedstad LF (2011) A model study of the Salish Sea estuarine circulation. J Phys Oceanogr 41:1125-1143

Tolimieri N, Andrews K, Williams G, Katz S, Levin PS (2009) Home range size and patterns of space use by lingcod, copper rockfish and quillback rockfish in relation to diel and tidal cycles. Mar Ecol Prog Ser 380:229-243

Submitted: October 24, 2011; Accepted: April 26, 2012

Proofs received from author(s): May 14, 2012 